Abstracta Iranica Iranica

Revue bibliographique pour le domaine irano-aryen

Volume 34-35-36 | 2017

Comptes rendus des publications de 2011-2013

\title{
Nils Arne Pedersen, John Møller Larsen. Manichaean Texts in Syriac: First Editions, New Editions and Studies
}

Christelle Jullien

\section{OpenEdition \\ 12 Journals}

Édition électronique

URL : http://journals.openedition.org/abstractairanica/41264

DOI : 10.4000/abstractairanica. 41264

ISSN : 1961-960X

\section{Éditeur :}

CNRS (UMR 7528 Mondes iraniens et indiens), Éditions de l'IFRI

\section{Référence électronique}

Christelle Jullien, « Nils Arne Pedersen, John Møller Larsen. Manichaean Texts in Syriac: First Editions, New Editions and Studies », Abstracta Iranica [En ligne], Volume 34-35-36 | 2017, document 1, mis en ligne le 15 juillet 2016, consulté le 05 octobre 2020. URL : http://journals.openedition.org/ abstractairanica/41264; DOI : https://doi.org/10.4000/abstractairanica.41264

Ce document a été généré automatiquement le 5 octobre 2020.

Tous droits réservés 


\title{
Nils Arne Pedersen, John Møller Larsen. Manichaean Texts in Syriac: First Editions, New Editions and Studies
}

\author{
Christelle Jullien
}

\section{RÉFÉRENCE}

Nils Arne Pedersen, John Møller Larsen. Manichaean Texts in Syriac: First Editions, New Editions and Studies. Turnhout, Brepols, 2013, x-396 p. (Corpus Fontium Manichaeorum : Series Syriaca)

1 Les fragments syriaque d'écriture manichéenne des collections payrologiques de Berlin et de Heidelberg n'avaient pas encore fait l'objet d'une édition critique intégrale. Les AA. livrent donc ici un matériau précieux, qui est aussi un témoignage de premier ordre sur le manichéisme dans son contexte araméen oriental. Un état de la recherche sur ce qu'on appelle le "sceau de Mani" est également proposé par Zsuzsanna Gulácsi qui aborde à nouveau cette question dans le Bulletin of the Asia Insitute 24, 2015, p. 161-186.

\section{AUTEURS}

CHRISTELLE JULLIEN

CNRS, Mondes iranien et indien, Paris 